\title{
Effect of Resistance Training and Tribulus Terrestris Consumption on Avoidance and Working Memory in Rats Exposed to Stanozolol
}

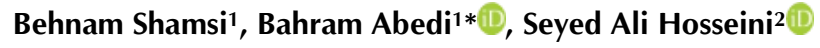 \\ 1 Department of Physical Education and Sport Sciences, Mahallat Branch, Islamic Azad University, Mahallat, Iran \\ 2 Department of Sports Physiology, Marvdasht Branch, Islamic Azad University, Marvdasht, Iran
}

\begin{abstract}
*Corresponding author:
Bahram Abedi, Department of

Physical Education and Sport

Sciences, Mahallat Branch, Islamic

Azad University, Mahallat, Iran

Email: abedi@iaumahallat.ac.ir
\end{abstract}

Received: 28 Jun. 2020

Accepted: 08 Sep. 2020

ePublished: 01 May. 2021

\begin{abstract}
Background and Objective: Abuse of androgenic-anabolic steroids is associated with cognitive impairment in athletes; however, the beneficial effects of herbs and exercise on memory improvement have been reported in this regard.

This study aimed to investigate the effect of eight weeks of resistance training (RT) with Tribulus Terrestris (TT) consumption on avoidance and working memory in rats exposed to stanozolol (S).

Materials and Methods: In this experimental study, 35 male rats were divided into seven groups of five animals including: 1) sham (normal saline) (Sh), 2) S, 3) S+100 mg/kg TT (STT100), 4) S+50 $\mathrm{mg} / \mathrm{kg}$ TT (STT50), 5) S+RT (SRT), 6) S+RT+100 mg/kg TT (SRTTT100), and 7) S+RT+50 mg/kg TT (SRTTT50). During eight weeks, groups 5-7 performed three sessions of weekly RT at an intensity of $30 \%$ to $100 \%$ of body weight, and groups $3,4,6$, and 7 received $50 \mathrm{mg} / \mathrm{kg}$ and $100 \mathrm{mg} / \mathrm{kg}$ TT peritoneally per day. The avoidance and working memory were measured $24 \mathrm{~h}$ after the last training session using shuttle box and $\mathrm{Y}$ maze tests, respectively.

Results: The step-through latency (STL) and percentage of non-repetitive alternations were significantly higher in the RT $(\mathrm{P} \leq 0.05)$, STT100 ( $\mathrm{P} \leq 0.05)$, and SRTTT100 ( $\mathrm{P} \leq 0.05)$ groups. Additionally, the time spent in the dark compartment (TDC) was shorter than that in the $\mathrm{S}$ group. Moreover, PA levels were significantly higher in the SRTTT50 group, compared to that in the S group $(P \leq 0.05)$. The RT and $100 \mathrm{mg} / \mathrm{kg}$ TT significantly increased the $\mathrm{STL}$, reduced TDC, and increased the non-repetitive percentage of alternation (PA) $(\mathrm{P} \leq 0.05)$. Moreover, RT with $100 \mathrm{mg} / \mathrm{kg}$ TT significantly increased STL, decreased TDC, and increased PA ( $\mathrm{P} \leq 0.05)$, while RT with 50 $\mathrm{mg} / \mathrm{kg}$ TT only increased PA ( $\mathrm{P} \leq 0.05)$.

Conclusions: The RT and TT consumption have a synergistic effect on memory improvement in rats exposed to S; however, it should be noted that the TT consumption is dose-dependent.

Keywords: Memory, Resistance training, Stanozolol, Tribulus terrestris
\end{abstract}

Background

Anabolic-androgenic steroids are a broad variety of testosterone derivatives that are used to treat some diseases, such as male infertility, kidney disease, aplastic anemia, osteoporosis, and AIDS, due to the synthetic effects [1-3]. However, studies show that illegal doses of these anabolic medications are usually used 10 to 100 times more than the usual amount in athletes and non-athletes [2]. Therefore, AAS abuse has become a global health problem [1, 2]. As a result, long-term use of AASs causes physical disorders in one out of three consumers. In other words, long-term and high-dose consumption of AASs leads to hypothalamic-pituitary-gonadal axis disorders [3]. Moreover, the abuse of stanozolol, as a member of the AAS family, causes behavioral disorders, such as depression, anxiety, and aggression, during consumption [4]. Limited studies have investigated the effect of AASs on the central nervous system; however, AASs appear to expose the nervous system to damage by increasing oxidative stress and metabolic disorders, stimulating the extracellular death pathway, as well as reducing neurotrophins in the hippocampus and the prefrontal cortex [4]. Among AASs, stanozolol also increases plasma corticosteroid levels by reducing the reluctant receptors of corticosteroids in the hippocampus that ultimately leads to cognitive impairment in the individual [4].

In addition, researchers have shown that the use of stanozolol in athletes has adverse effects on their nervous system, brain, heart, and liver. Moreover, according to some studies, high-intensity training and stanozolol abuse impair nerve cell redox [5]. The use of AASs is also prevalent in non-athletes for weight loss purposes and improvement of physical function, and studies revealed that their 
abuse in non-athletes had more side effects than those among athletes [6].

Among the medicinal plants, Tribulus Terrestris (TT) from the Zygophyllaceae family has good effects on central nervous system disorders due to compounds, such as steroidal saponins, flavonoids, spirostanol, furanostol steroids, alkaloids, and cinnamic acid [7]. The researchers believe that TT, with its anti-inflammatory and antioxidant effects, can have protective effects on neurons [8]; however, the effects of this medicinal plant appear to be dose-dependent. It has been shown that the consumption of 100, 200, and $400 \mathrm{mg} / \mathrm{kg}$ TT extract for 14 days leads to improved memory and learning in rodents. Furthermore, a dose of 400 $\mathrm{mg} / \mathrm{kg}$ had a more favorable effect on memory improvement [9], and a consumption of 150 and $300 \mathrm{mg} / \mathrm{kg}$ T'T for 30 days improved the memory function of diabetic rats [10]. In addition, this medicinal plant has long been used to improve physical composition, strength, and muscle mass along with sports activities [11]. It seems that the consumption of TT along with physical activity can synergistically improve growth hormone and insulin-like growth factor-1 hormone, which have beneficial effects on athletes by improving lipid metabolism [12]. In this regard, the researchers showed that resistance training (RT) improved memory in elderly males [13, 14] and females [15]. Given the adverse effects of AAS on memory and learning, as well as a dearth of research about the protective effects of TT extract against stanozolol, it seems that investigations in this regard can provide a suitable solution for athletes with behavioral problems caused by stanozolol abuse.

\section{Objectives}

The present study aimed to investigate the effect of eight weeks of RT with TT extract on avoidance and working memory of rats exposed to stanozolol.

\section{Materials and Methods}

In this experimental study, 35 Sprague Dawley rats were purchased and transferred to the laboratory. After one week of adaptation to the laboratory environment, the rats were divided into seven groups of five animals per group. The groups included: 1) sham (normal saline) (Sh), 2) stanozolol
(S), 3) S+100 mg/kg TT (STT100), 4) S+50 mg/kg T'T (STT50), 5) S+RT (SRT), 6) S+RT+100 mg/kg T'T (SRTTT100), and 7) S+RT+50 mg/kg T'T (SRT'T'T50). Over eight weeks, groups 2-7 received $5 \mathrm{mg} / \mathrm{kg} /$ day stanozolol peritoneally [16]. Moreover, groups 5-7 performed RT three sessions per week [17], and groups 3, 4, 6, and 7 received specific doses of T'T peritoneally [18]. The Shuttle Box and $\mathrm{Y}$ Maze tests were used to evaluate avoidance and working memory $48 \mathrm{~h}$ after the last training session and injection of stanozolol and T'T. Table 1 tabulates the research design.

\section{Resistance Training Protocol}

The rats performed RT using a one-meter-high ladder with a distance of $4 \mathrm{~cm}$ between the stairs and a slope of $85^{\circ}$. The RT began at $30 \%$ of body weight in the first week and ended at $100 \%$ of the bodyweight of rats in the eighth week. It is noteworthy to mention that the rats climbed four repetitions without weights from the training ladder to warm up at the beginning of the training. Moreover, the training in each session included four sets (the first: $50 \%$, the second: $75 \%$, the third: $90 \%$, and the fourth: $100 \%$ of the weight set for that week) and two repetitions (climbing the stairs twice). The intervals between each set and repetition were 2 to $3 \mathrm{~min}$ and 40 to $60 \mathrm{sec}$, respectively [17].

\section{Preparation of Tribulus Terrestris extract}

The percolation method was used to prepare T'T extract. For this purpose, a sufficient amount of T'T plant was prepared from Jihad Keshavarzi of Marvdasht, Iran. After confirmation by botanists, this plant was dried and ground using an electric mill. Subsequently, $100 \mathrm{~g}$ of T'T powder was placed in $80 \mathrm{ml}$ of $70 \%$ alcohol. This solution was then stored in the laboratory at $25^{\circ} \mathrm{C}$ for 3 days to be completely soaked. Afterward, it was mixed well with the help of a stirrer to obtain a uniform state, and the mixture was filtered through a filter. In the next stage, the resulting mixture was concentrated by a rotary device, and all the moisture was taken using a desiccator to obtain an extract with high viscosity. Following that, the rats received the extract by normal saline at doses of 50 and 100 $\mathrm{mg} / \mathrm{kg}$ per day $[16,19]$.

Table 1. Research design

\begin{tabular}{lcc}
\hline Stanozolol & Eight weeks & $5 \mathrm{mg} / \mathrm{kg} / \mathrm{day}$ \\
Resistance training & Eight weeks & Three sessions per week \\
$\mathbf{5 0 ~} \mathbf{~ m g / k g}$ Tribulus terrestrial & Eight weeks & $50 \mathrm{mg} / \mathrm{kg} / \mathrm{day}$ \\
$\mathbf{1 0 0} \mathbf{~ m g / k g}$ Tribulus terrestrial & Eight weeks & $100 \mathrm{mg} / \mathrm{kg} / \mathrm{day}$ \\
& Accustomization session & $24 \mathrm{~h}$ after the last training session \\
Evaluation of avoidance memory & Memory Acquisition Tutorial & 30 min after the accustomization session \\
Evaluation of spatial memory & Evaluation of spatial memory & $24 \mathrm{~h}$ after memory acquisition tutorial session \\
& & $24 \mathrm{~h}$ after the last training session \\
\hline
\end{tabular}


Evaluation of avoidance memory

The avoidance memory test was performed in two days and two consecutive stages.

\section{Accustomization session}

All rats were placed in the laboratory at least $30 \mathrm{~min}$ before the onset of the experiment. Subsequently, each rat was placed in a light compartment, and after $5 \mathrm{sec}$, the guillotine door was opened and the animal was allowed to enter the dark compartment.

The initial delay time (the time to enter the dark compartment from the light compartment) was noted, and the criterion for the animal entering the dark compartment was the insertion of the hind legs into the compartment at which point the guillotine door was closed.

After $10 \mathrm{sec}$, the animal was returned to its cage, and the rats with a delay of more than $100 \mathrm{sec}$ were excluded from the experiment [20]. In the present study, two rats in the healthy control group did not enter the dark compartment after 100 seconds and were eliminated consequently.

\section{Memory Acquisition Tutorial}

The rat was placed in the light compartment again $30 \mathrm{~min}$ later, and after $5 \mathrm{sec}$, the guillotine door was opened, and as soon as the animal entered the dark compartment, the guillotine door was closed, and the animal was shocked through the floor bars (50 $\mathrm{Hz}, 1$ milliampere, 3 seconds). Afterward, it was returned to its cage after 15 to $20 \mathrm{sec}$. The animal was placed in a light container again two minutes later. If the animal entered the black hole again, it would be shocked again. However, if animals had a memory and did not enter the dark compartment for two min, the test would be terminated, and the rats would be returned to the cage [20].

\section{Memory Recovery Test}

A recovery test was performed $24 \mathrm{~h}$ after the memory acquisition tutorial session to check the animal's long-term memory. At this stage, each animal was placed in a light compartment, and after $20 \mathrm{sec}$, the guillotine door was opened, and the step-through latency (STL) in the dark compartment, as well as the time spent in the dark compartment (TDC) for each rat, were recorded during the test. The test lasted 5 min [20], and after the test, the rats were returned to the cage. It should be noted that this step was performed without electrical stimulation and STL and TDC were measured for each rat for $300 \mathrm{sec}$. Therefore, the unit of measurement of these two variables was regarded as seconds. This test is a valid scale that is recommended by many researchers to measure avoidance memory [21-23].
Evaluation of spatial memory

The Y-shaped maze device test consists of three arms and is made of Medium Density Fibreboard. Each arm is $46 \mathrm{~cm}$ long, $15 \mathrm{~cm}$ high, and $15 \mathrm{~cm}$ wide; moreover, the arms are placed at equal angles to each other and connected through a central area. To perform the test, the rat was first placed at the end of an arm, and it was possible to access all areas of the maze in a 5 -min period. The number of times the animal entered each arm was observed and recorded in this study. The entry of the animal into the arm was considered when the animal's hind legs were completely inside the arm, and alternative behaviors were considered successful and consecutive entrances (series) into all arms in the overlapping 3 sets. Accordingly, the observed percentage of alternation (PA) was calculated as the maximum frequency (total number of arms imported) multiplied by 100 [20].

\section{Data Analysis}

The data were analyzed in SPSS software (version 22) through Shapiro-Wilk and one-way ANOVA with Tukey's post-hoc tests. A p-value equal/less than 0.05 was considered statistically significant.

\section{Results}

Figures 1-3 present the STL, TDC, and PA levels of the research groups, respectively. The results of the one-way ANOVA test showed a significant difference among the research groups in terms of STL $(\mathrm{F}=8.148 ; \mathrm{P}=0.001)$ and TDC $(\mathrm{F}=22.10$; $\mathrm{P}=0.001)$. Furthermore, the results of Tukey's posthoc test revealed that the STL levels in the S group were significantly lower than those in the Sh group

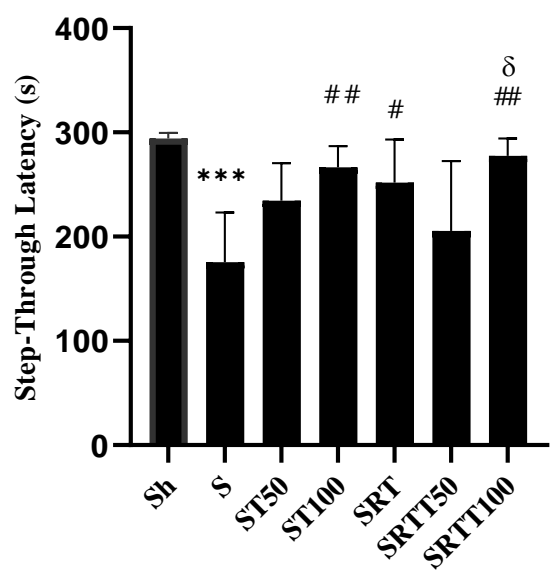

Figure 1. Levels of step-through latency in the dark compartment in the seven research groups

*** ( $\mathrm{P} \leq 0.001)$ showing a significant decrease, compared to that in the Sh group

\#\# $(P \leq 0.01)$ and \# $(P \leq 0.05)$ showing a significant increase, compared to that in the $\mathrm{S}$ group

$\delta(P \leq 0.05)$ showing a significant increase, compared to that in the SRTTT50 group 


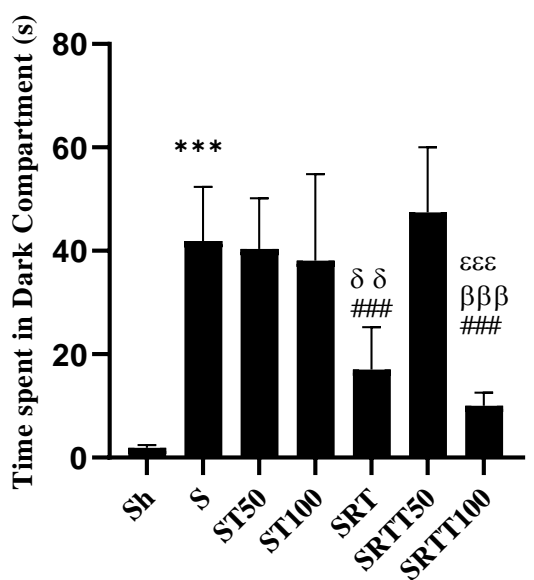

Figure 2. Levels of time spent in the dark compartment in the seven research groups

*** $(\mathrm{P} \leq 0.001)$ showing a significant increase, compared to that in the Sh group

\#\# $(P \leq 0.01)$ showing a significant decrease, compared to that in the $S$ group

$\delta \delta(\mathrm{P} \leq 0.01)$ showing a significant decrease, compared to that in the STT50, STT100, and SRTTT50 groups

$\beta \beta \beta(P \leq 0.001)$ showing a significant decrease, compared to that in the STT100 group

$\varepsilon \varepsilon \varepsilon(\mathrm{P} \leq 0.001)$ showing a significant decrease, compared to that in the SRTTT50 group

$(\mathrm{P}=0.001)$; however, the STL in the ST100 $(\mathrm{P}=0.0014), \quad$ SRT $\quad(\mathrm{P}=0.01)$, and SRTTT100 $(\mathrm{P}=0.003)$ groups were significantly higher than those in the S group. Moreover, the STL in the SRTTT100 group was significantly higher than that in the SRTTT50 group $(\mathrm{P}=0.018)$ (Figure 1).

The TDC levels in the $\mathrm{S}$ group were significantly higher than those in the Sh group $(\mathrm{P}=0.001)$. However, the TDC levels in the SRT $(\mathrm{P}=0.001)$ and SRTTT100 $(\mathrm{P}=0.001)$ groups were significantly lower than those in the $\mathrm{S}$ and SRT groups, compared to the STT50 (P=0.0018), STT100 $(\mathrm{P}=0.006)$, and SRTTT50 $(\mathrm{P}=0.001)$ groups. Additionally, the TDC in the SRTTT100 group was significantly lower than that in the STT100 $(\mathrm{P}=0.001)$ group. Moreover, the TDC in the SRTTT100 group was significantly lower than that in the SRTTT50 group $(\mathrm{P}=0.001)$ (Figure 2).

The results of the one-way ANOVA test indicated a significant difference among the research groups in terms of PA $(\mathrm{P}=0.001, \mathrm{~F}=5.83)$. Furthermore, the $\mathrm{PA}$ levels in the $\mathrm{S}$ group were significantly lower than those in the Sh group $(\mathrm{P}=0.02)$. However, this corresponding value was higher in the STT100 $(\mathrm{P}=0.004)$, SRT $(\mathrm{P}=0.001)$, SRTTT50 ( $\mathrm{P}=0.001)$, and SRTTT100 $(\mathrm{P}=0.014)$ groups, compared to that in the $\mathrm{S}$ group (Figure 3).

\section{Discussion}

The results of the present study showed that the RT increased the STL in the dark compartment, reduced the TDC, and increased the percentage of

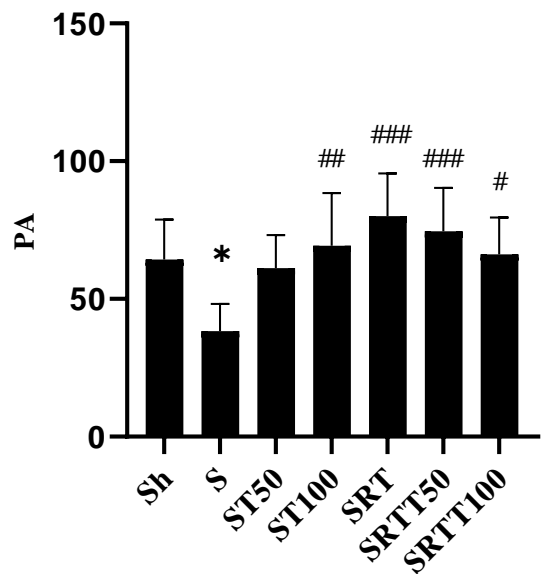

Figure 3. Levels of the non-repetitive percentage of alternation in the seven research groups

* ( $\mathrm{P} \leq 0.001)$ showing a significant decrease, compared to that in the Sh group

\#\# \# $(P \leq 0.001$, \#\# $(P \leq 0.01)$, and \# $(P \leq 0.05)$ showing a significant increase, compared to that in the $\mathrm{S}$ group

non-repetitive alternations in rats exposed to stanozolol. Studies investigating the effect of longterm use of AAS on the structure of the brain show that exposure to these anabolic medications can lead to the induction of the extrinsic pathway of apoptosis through the mechanism of increased amyloid-beta and increased oxidative stress, thereby creating different structural abnormalities in the brain [2]. The studies also found that AASs abuse with oxidative stress mechanisms led to the disruption of dopamine receptors and increased dopamine secretion from various parts of the brain and $\mathrm{C} 1$ hippocampus while inhibiting dopamine-like D1 receptors.

As a result, they reduced dopaminergic function and disrupted the androgen regeneration system. All of these events led to decreased neuronal flexibility and affected learning and memory [24]. In this regard, the results of the studies demonstrated that long-term use of AAS led to a decrease in the number of healthy cells in the cortex, cerebellum, and hippocampus [2]. The injections of $7.5 \mathrm{mg} / \mathrm{kg}$ testosterone for 14 days also impaired learning in rats, thereby increasing the rate of cognitive impairment [24]. However, the mechanism of exercise activity has been known to increase neurotrophins, reduce oxidative stress, improve vascular circulation, and increase neuronal plasticity in the central nervous system [25].

As a result, a long-term exercise in young and middle-aged people led to increased levels of brainderived neurotrophic factor (BDNF) and cathepsin $\mathrm{B}$; moreover, it decreased malondialdehyde and lipid peroxidation [25]. On the other hand, studies show that the rate of damage to the nervous system was less observed in athletes consuming AAS. It seems 
that physical activity increases the body's metabolism and interaction with anabolic steroids and partly increases androgen receptors, which can improve the metabolism of lipoproteins in blood vessels and reduce the extent of AAS damage relative to non-athlete individuals [26]. However, the impact of resistance activity on memory and learning in human and animal models exposed to $\mathrm{S}$ has not been yet fully understood.

The results of the present study showed that the consumption of TT with a dose of $100 \mathrm{mg} / \mathrm{kg}$ increased the STL in the dark compartment and increased the percentage of non-repetitive alternations; nonetheless, the dose of $50 \mathrm{mg} / \mathrm{kg}$ had no significant effect on the research variables. Additionally, the consumption of T'T decreased the levels of nuclear factor kappa beta $(\mathrm{NF}-x \mathrm{~B})$, tumor necrosis factor-alpha, interleukin 1-beta, and malondialdehyde (MDA). However, it increased the peroxisome proliferator-activated receptor-gamma $(\operatorname{PPAR} \gamma)$, anti-apoptotic protein $\mathrm{Bcl}-2$, and superoxide dismutase, thereby inducing its protective effects on the central nervous system and hippocampus [8, 27].

In the same line, the studies have shown that TT increased the expression of cyclooxygenase- 2 and the enzyme nitric oxide synthase, thereby improving the function of the glia and increasing the levels of neurotrophin [27]. Moreover, the findings of an in vivo and in vitro study indicated that $50 \mathrm{mg} / \mathrm{kg}$ and $100 \mathrm{mg} / \mathrm{kg}$ aqueous extract of T'T with an antiapoptotic mechanism inhibited caspases, increased BDNF, and decreased NF- $x \mathrm{~B}$ leading to the improved neuronal function [28]. In line with the present study, the consumption of 14 days of $200 \mathrm{mg} / \mathrm{kg}$ TT improved the memory of rats [8]. Additionally, the consumption of 150 and 300 $\mathrm{mg} / \mathrm{kg}$ of TT extract also improved memory levels and learning of diabetic rats [10]. On the other hand, TT extract also reduced MDA levels and increased the percentage of non-repetitive alternations in diabetic rats [29].

The results showed that RT with $100 \mathrm{mg} / \mathrm{kg}$ TT increased the STL in the dark compartment, reduced the TDC, and also increased the percentage of non-repetitive alternations, whereas RT with 50 $\mathrm{mg} / \mathrm{kg}$ TT only increased the percentage of nonrepetitive alternations.

Studies show that exercise can help enhance memory by improving neurotrophins and vascular circulation, reducing oxidative stress, and increasing neuronal plasticity [25, 26]. The dose-dependent consumption of TT also has a protective effect on the central nervous system and hippocampus and improve memory by reducing the levels of inflammatory agents, antioxidants, and oxidative stress, followed by an increase in Peroxisome Proliferator Activated Receptor Gamma, B-cell lymphoma 2, cyclooxygenase-2 expression, nitric oxide synthase enzyme, and neurotrophins [8, 27]. Furthermore, in line with the results of the present study, some studies have reported the desired effect of T'T extract with high doses $[8,27,28]$. Therefore, it seems that the effects of exercise and higher doses of TT extract on avoidance and working memory are more favorable than RT and RT with $50 \mathrm{mg} / \mathrm{kg}$ TT. Due to the role of neurotrophins, inflammatory factors, and oxidative-antioxidant stress system on memory disorders caused by stanozolol, one of the limitations of the present study is the lack of evaluation of these physiological variables; accordingly, it is recommended that future studies evaluate these physiological variables.

\section{Conclusions}

It seems that RT with T'T administration has synergistic effects on improving memory in rats exposed to S; however, it is noteworthy to mention that the effect of T'T is dose-dependent.

\section{References}

1. Tabor J, Wright D, Christensen J, Zamani A, Collins R, Shultz SR, et al. Examining the effects of anabolicandrogenic steroids on repetitive mild traumatic brain injury (RmTBI) outcomes in adolescent rats. Brain Sciences. 2020; 10(5):258. [DOI:10.3390/brainsci10050258] [PMID] [PMCID]

2. Bjwrnebekk A, Walhovd KB, Jwrstad ML, Due-Twnnessen P, Hullstein IR, Fjell AM. Structural brain imaging of longterm anabolic-androgenic steroid users and nonusing weightlifters. Biological Psychiatry. 2017; 82(4):294-302. [DOl:10.1016/j.biopsych.2016.06.017] [PMID]

3. Silva DK, Esteves A, Guerra FDR, Soares EA, Nogueria DA, Marques PP, et al. Chronic use of anabolic steroids and the effects on the neuronal density of the cerebral cortex and hippocampus in mice. American Journal of Sports Science. 2018; 6(3):122-9. [DOI:10.11648/j.ajss.20180603.18]

4. Karimooy FN, Bideskan AE, Pour AM, Hoseini SM. Neurotoxic effects of stanozolol on male rats hippocampi: does stanozolol cause apoptosis? Biomolecular Concepts. 2019; 10(1):73-81. [DOI:10.1515/bmc-2019-0009] [PMID]

5. Arazi $H$, Mohammadjafari $H$, Asadi A. Use of anabolic androgenic steroids produces greater oxidative stress responses to resistance exercise in strength-trained men. Toxicology Reports. 2017; 4:282-6. [DOI:10.1016/j.toxrep.2017.05.005] [PMID] [PMCID]

6. Kersey RD, Elliot DL, Goldberg L, Kanayama G, Leone JE, Pavlovich $M$, et al. National athletic trainers' association position statement: anabolic-androgenic steroids. Journal of Athletic Training. 2012; 47(5):567-88. [DOI:10.4085/10626050-47.5.08] [PMID] [PMCID]

7. Chauhdary Z, Saleem U, Ahmad B, Shah S, Shah MA. Neuroprotective evaluation of Tribulus terrestris L. in aluminum chloride induced Alzheimer's disease. Pakistan Journal of Pharmaceutical Sciences. 2019; 32(2 Suppl): 80516. [PMID]

8. Zhu W, Du Y, Meng H, Dong Y, Li L. A review of traditional pharmacological uses, phytochemistry, and pharmacological activities of Tribulus terrestris. Chemistry Central Journal. 2017; 11(1):60. [DOI:10.1186/s13065-017-0289-x] [PMID] [PMCID]

9. Prabhu N, Hadigal S. Effect of Tribulus terrestris on learning and memory in wistar rats. Pharmacognosy Journal. 2014; 6(4):68-71. [DOI:10.5530/pj.2014.4.10]

10. Vangalapati B, Manjrekar PA, Hegde A, Ullal S. Land 
caltrop (Tribulus terrestris) fruit extract improves learning, memory and cognitive flexibility in StreptozotocinNicotinamide induced diabetes animal model. International Journal of Pharmaceutical Sciences Review and Research. 2016; 38(2):243-7.

11. Antonio J, Uelmen J, Rodriguez R, Earnest C. The effects of Tribulus terrestris on body composition and exercise performance in resistance-trained males. International Journal of Sport Nutrition and Exercise Metabolism. 2000; 10(2):208-15. [DOI:10.1123/ijsnem.10.2.208] [PMID]

12. Wilk M, Michalczyk M, Chycki J, Czuba M, Roczniok R, Gołaś $\mathrm{A}$, et al. Endocrine responses to physical training and tribulus terrestris supplememtation in middle-age men. Central European Journal of Sport Sciences and Medicine. 2016; 13(1):65-71. [DOI:10.18276/cej.2016.1-06]

13. Marston KJ, Peiffer JJ, Rainey-Smith SR, Gordon N, Teo SY, Laws SM, et al. Resistance training enhances delayed memory in healthy middle-aged and older adults: a randomised controlled trial. Journal of Science and Medicine in Sport. 2019; 22(11):1226-31. [DOI: 10.1016/j.jsams.2019.06.013] [PMID]

14. Eckardt N, Braun C, Kibele A. Instability resistance training improves working memory, processing speed and response inhibition in healthy older adults: a double-blinded randomised controlled trial. Scientific Reports. 2020; 10(1):1-12. [DOI:10.1038/s41598-020-59105-0] [PMID] [PMCID]

15. Best JR, Chiu BK, Hsu CL, Nagamatsu LS, Liu-Ambrose T. Long-term effects of resistance exercise training on cognition and brain volume in older women: results from a randomized controlled trial. International Neuropsychological Society. 2015; 21(10):745-56. [DOI:10.1017/S1355617715000673] [PMID]

16. Dos Santos GB, Rodrigues MJM, Gonzalves EM, Cintra Gomes Marcondes MC, Areas MA. Melatonin reduces oxidative stress and cardiovascular changes induced by stanozolol in rats exposed to swimming exercise. The Eurasian Journal of Medicine. 2013; 45(3):155-62. [DOI:10.5152/eajm.2013.33] [PMID] [PMCID]

17. Dehghan F, Hajiaghaalipour F, Yusof A, Muniandy S, Hosseini SA, Heydari S, et al. Saffron with resistance exercise improves diabetic parameters through the GLUT4/AMPK pathway in-vitro and in-vivo. Scientific Reports. 2016; 6:25139. [DOI:10.1038/srep25139] [PMID] [PMCID]

18. Nishchal BS, Rai S, Prabhu MN, Ullal SD, Rajeswari S, Gopalakrishna HN. Effect of Tribulus terrestris on haloperidol-induced catalepsy in mice. Indian Journal of Pharmaceutical Sciences. 2014; 76(6):564-7. [PMID] [PMCID]
19. Hejazi L, Hosseini SE. The effect of tribulus terrestris extract on hepatic complications due to the gelofen consumption in adult female rats. Journal of Fasa University of Medical Sciences. 2016; 6(2):155-61.

20. Zavvari F, Karimzadeh F. A review on the behavioral tests for learning and memory assessments in rat. The Neuroscience Journal of Shefaye Khatam. 2017; 5(4):110-24.

21. Farzad P, Rahimi R, Ebrahimi SA, Aghajani F, Mousavi Z, Najafizadeh $P$. The effect of voluntary exercise and prenatal exposure to sodium valproate on learning, memory, and anxiety of rats' offspring. Iranian Journal of Medical Sciences. 2020; 45(1):32-40. [DOI:10.30476/ijms.2019.45314] [PMID] [PMCID]

22. Bagha N, Edalatmanesh MA. Effectiveness of erythropoietin on working memory, passive avoidance learning and anxiety-like behaviors in prenatal food restriction model. Report of Health Care. 2018; 4(1):36-43.

23. Heshmati A, Komaki A, Faraji N, Karami J. Effects of butter and cheese on memory and learning in rats. Nutrition and Food Sciences Research. 2020; 7(1):17-24. [DOI: 10.29252/nfsr.7.1.17]

24. Wood RI, Serpa RO. Anabolic-androgenic steroid abuse and cognitive impairment: testosterone IMPAIRS biconditional task performance in male rats. Behavioural Brain Research. 2020 379:112339. [DOI: 10.1016/j.bbr.2019.112339] [PMID]

25. De la Rosa A, Solana E, Corpas R, Bartrūs-Faz D, Pallas M Vina J, et al. Long-term exercise training improves memory in middle-aged men and modulates peripheral levels of BDNF and Cathepsin B. Scientific Reports. 2019; 9(1):3337. [DOI: 10.1038/s41598-019-40040-8] [PMID] [PMCID]

26. Hartgens F, Kuipers H. Effects of androgenic-anabolic steroids in athletes. Sports Medicine. 2004; 34(8):513-54. [DOI: 10.2165/00007256-200434080-00003] [PMID]

27. Alzahrani S, Ezzat W, Elshaer RE, Abd El-Lateef AS, Mohammad HMF, Elkazaz AY, et al. Standarized Tribulus terrestris extract protects against rotenone-induced oxidative damage and nigral dopamine neuronal loss in mice. Journal of Physiology and Pharmacology. 2018; 69(6):679-994. [DOI: 10.26402/jpp.2018.6.14] [PMID]

28. Ranjithkumar R, Alhadidi Q, Shah ZA, Ramanathan M Tribulusterine containing tribulus terrestris extract exhibited neuroprotection through attenuating stress kinases mediated inflammatory mechanism: in vitro and in vivo studies. Neurochemical Research. 2019; 44(5):1228-42. [DOI: 10.1007/s11064-019-02768-7] [PMID]

29. Roghani M, Omid Malayeri S, Malayeri S. Effect of tribulus terrestris oral feeding on learning and memory in streptozotocin-diabetic rats: investigating the role of lipid peroxidation. Journal of Guilan University of Medical Sciences. 2013; 22(85):88-95. 